\title{
Duplicação de sujeitos pré-verbais no francês, no inglês e no português brasileiro: uma análise não-unificada
}

\author{
Duplication of preverbal subjects in French, English \\ and Brazilian Portuguese: a non-unified analysis
}

\section{Cláudia Roberta Tavares Silva} UFRPE

\section{Abstract}

In this paper I develop a comparative study between English, French and Brazilian Portuguese (henceforth BP) about the constructions with double preverbal subjects in finite declarative sentences. It is common to assume that these constructions are similar in BP and French because the subjects are left dislocated, a fact that derives from the Avoid Principle Pronoun. With respect to English, the situation is the same: the preverbal subjects occupy an A-bar position because they are duplicated by a coreferent pronoun that checks the EPP-feature. Contrary this analysis, my principal aim is to present syntactic, semantic and prosodic evidences that show that constructions with double preverbal subjects in BP do not imply left dislocation of these subjects necessarily, contrary to English and French. For this analysis, I adopt the Distributed Morphology framework.

Keywords

Variation; double preverbal subjects; inflectional morphology 


\section{Resumo}

Neste artigo realizo um estudo comparativo entre o inglês, o francês e o português brasileiro (PB) sobre as construções com sujeitos préverbais duplicados em sentenças declarativas finitas. É comumente assumido que essas construções são similares em PB e em francês porque os sujeitos estão deslocados à esquerda, um fato que deriva do Princípio Evite Pronome. Quanto ao inglês, a situação é similar: os sujeitos pré-verbais ocupam uma posição A-barra por serem duplicados por um pronome co-referente que checa o traço-EPP. Contrariamente a essa análise, meu principal objetivo é apresentar evidências sintáticas, semânticas e prosódicas que mostram que construções com sujeitos pré-verbais duplicados em PB não implicam, necessariamente, deslocamento à esquerda, ao contrário do que ocorre no inglês e no francês. Para essa análise, adoto o quadro teórico da Morfologia Distribuída.

\section{Palavras-chave}

Variação; sujeitos pré-verbais duplicados; morfologia flexional 


\section{INTRODUÇÃO}

$\neg$ em sido comumente assumido que sujeitos pré-verbais no português brasileiro (doravante $\mathrm{PB}$ ) estão deslocados à esquerda, sendo duplicados por um pronome co-referente nulo ou preenchido (cf. FIGUEIREDO SILVA, 1996; BARBOSA; DUARTE; KATO, 2001; DUARTE, 2000; BRITTO, 2000; KATO, 2000, entre outros.). Uma explicação para essa análise está relacionada à proposta já formulada por Pontes (1986), segundo a qual essa língua é orientada para o tópico.

Muito produtivas na gramática do $\mathrm{PB}$, as construções com duplicação do sujeito $^{1}$ ocorrem quer em sentenças principais (cf. (1)), quer em sentenças subordinadas (cf. (2)), podendo haver ou não um corte entoacional, representado graficamente pela vírgula. Além disso, outros constituintes podem intervir entre o sujeito pré-verbal e o pronome que o duplica (cf. (3)), conforme observa Duarte (2000, p. 28):

(1) A Clarinha $a_{i}$ ela cozinha que é uma maravilha.

(2) Eu acho que um trabalho sério ${ }_{i}$ ele $_{i}$ teria que começar por aí.

(3) Você $\hat{i}_{i}$, no Canadá, você $\hat{i}_{i}$ pode ser o que quiser.

Britto (op. cit., p. 202) verifica que, em se tratando de sentenças com leituras genéricas e universais que expressam um juízo categórico, pode haver duplicação do sujeito em PB (cf. (4)), uma situação que contraria o que é observado por De Cat (2003, p. 9) no francês (cf. (5)):

(4) $[\text { Todo homem }]_{\mathrm{i}}$ ele $_{\mathrm{i}}$ odeia se sentir fraco.

(5) *Tout homme, il est mortel.

"Todo homem, ele é mortal." 
No que concerne ao português europeu (doravante PE), construções com sujeitos pré-verbais deslocados à esquerda são marcadas. Esses sujeitos necessitam de uma interpretação de foco, não podendo haver adjacência sintática entre eles e o pronome resumptivo, sendo necessária, portanto, a presença de um corte entoacional:

(6) a. O João... ele estupidamente entornou o café.

(COSTA, 2003, p. 39)

b. A: Quem foi à praia?

B: O Pedro...ele foi, os outros não sei.

(COSTA; GALVES, 2002, p. 119)

Além do contexto marcado ao qual os sujeitos deslocados em PE estão submetidos, as sentenças subordinadas com esses sujeitos não são produzidas pela gramática dessa língua (cf. (7)), como observa Galves (1998). Contudo, conforme atestam Costa e Galves (op. cit.), a posição pós-verbal está disponível para o pronome resumptivo nessa gramática (cf. (8)), ao contrário do que ocorre em PB, língua que não produz inversão sujeito-verbo com verbos (in)transitivos, exceto com verbos inacusativos (cf. KATO, 1999; SILVA, 2004):

(7) Eu acho que o povo brasileiro ele tem uma grave doença. (PB/*PE)

(8) O Pedro, leu ele o livro. (*PB/PE)

(Ibid., p. 115, 118)

Segundo é observado por Duarte (2000, p. 27), a emergência de construções com duplicação do sujeito e a não-produção da ordem VS com verbos (in)transitivos no $\mathrm{PB}$ evidenciam que essa língua está caminhando para se tornar uma língua não-pro-drop, como o francês e o inglês, em virtude do enfraquecimento de sua morfologia de flexão verbal e conseqüente perda do Princípio Evite Pronome.

A autora observa ainda que o processo de perda de sujeitos nulos referenciais no PB assemelha-se ao que foi verificado por Vance (1989) no francês medieval. Nesta língua, pelo fato de a morfologia flexional começar a se tornar defectiva no período medieval, sujeitos nulos referenciais começam a ser pouco produtivos, e passam a surgir construções com duplicação do 
sujeito, o que culminará mais tarde na formação de um sistema de clíticos sujeitos bastante produtivos.

Diante das propostas apresentadas, assumirei, parcialmente, neste trabalho, a proposta de Duarte (2000), segundo a qual a duplicação do sujeito está relacionada com a perda morfológica de algumas pessoas do paradigma flexional no PB. Não obstante, afasto-me da perspectiva de análise dessa autora por argumentar que essa duplicação não se relaciona necessariamente com a perda do Princípio Evite Pronome. Ademais, proporei uma análise nãounificada para as construções de duplicação do sujeito nessa língua, ao compará-las com as do francês e do inglês. Será argumentado que, nessas duas últimas línguas, os sujeitos são, de fato, tópicos marcados por estarem deslocados à esquerda da frase.

Evidências de ordem sintática, prosódica e semântica indicam que, em certos contextos estruturais no PB, a duplicação do sujeito não corresponde à estratégia de topicalização. Nesses contextos, o sujeito e o pronome que o duplica estão na mesma posição-A, estando a marca de pessoa, cuja lexicalização é pós-sintática, ancorada no núcleo D. Para a realização dessa análise, com base num estudo já realizado por Costa, Duarte e Silva (2004), adotarei o quadro teórico da Morfologia Distribuída (cf. HALLE; MARANTZ, 1993 e EMBICK; NOYER, 2001).

\section{A ANÁLISE}

\subsection{Análises precedentes}

Em geral, tem sido assumido que construções com duplicação do sujeito no PB sejam da mesma natureza que as do francês por se tratar de duplicação de um constituinte deslocado à esquerda da frase que é retomado, no domínio intrafrásico, por um pronome fraco (XP), seguindo a classificação de Cardinaletti e Starke (1994). Vejam-se as seguintes configurações extraídas de Britto (2000, p. 203) que ilustram essa proposta de análise:

$$
\begin{array}{ll}
{\left[_ { \mathrm { XP } } \mathrm { DP } \left[_{\mathrm{IP}}\right.\right. \text { ele }} & [\mathrm{I}, \mathrm{V}(\ldots)]]] \\
{\left[_ { \mathrm { XP } } \mathrm { DP } \left[_{\mathrm{IP}} \mathrm{il}\right.\right.} & \left.\left.\left.{ }_{\mathrm{I}}, \mathrm{V}(\ldots)\right]\right]\right]
\end{array}
$$


Quanto às propriedades que caracterizam o pronome resumptivo como fraco no PB, Britto (2000), adotando a análise de Cardinaletti e Starke (op. cit.), estabelece distinção entre pronomes fracos e fortes. Um aspecto a ressaltar é que esses pronomes são quase homófonos nessa língua. Nas frases: (i) Ela ela preparou o jantar ontem e (ii) Você cê toca piano muito bem, o primeiro pronome é forte e o segundo é fraco pelas seguintes razões listadas por Britto (op. cit., p. 208-211):

a) Pronomes fortes podem receber acento enfático por ser o seu referente [+ animado] (cf. (10b)), ao contrário dos fracos (cf. (11b)) que nunca recebem tal acento:

(10) a. O JOÃO bebe demais (e não a Maria).

b. ELE bebe demais ( e não ela).

c. O João bebe demais.

d. Ele bebe demais.

(11) a. O CARRO bebe demais (e não a moto).

b. *ELE bebe demais (e não ela, a moto).

c. $\mathrm{O}$ carro bebe demais.

d. Ele bebe demais.

b) Pronomes fortes podem ser coordenados (cf. (12b)), ao contrário dos fracos (cf. (13b)):

(12) a. O João e a Maria estão bebendo demais.

b. Ele e ela estão bebendo demais.

(13) a. O carro e a moto estão bebendo demais.

b. *Ele e ela estão bebendo demais.

c) Pronomes fortes podem ser modificados (cf. (14b)), ao contrário dos fracos (cf. (15b)):

(14) a. Aqui em casa, só meu irmão bebe demais (o resto da família quase não bebe).

b. Aqui em casa, só ele bebe demais (o resto quase não bebe). 
(15) a. Aqui em casa, só o meu carro bebe muito (os outros são bem econômicos).

b. *Aqui em casa, só ele bebe muito (os outros são bem econômicos).

d) Pronomes fortes podem ocupar posições periféricas à frase (cf. (16b)), ao contrário dos fracos (cf. (17b)):

(16) a. O João o cabelo dele está horrível.

b. Ele, o cabelo dele está horrível.

(17) a. O carro, o motor dele está horrível.

b. *Ele, o motor dele está horrível.

e) Pronomes fracos não-referenciais, a saber, pronomes expletivos, aparecem não realizados foneticamente no $\mathrm{PB}$ :

(18) $\mathrm{pro}^{*}$ *ele choveu bastante hoje.

f) Pronomes fracos sofrem redução fonológica, ao contrário dos fortes:

(19) a. segunda pessoa do singular: [vo'se]- - [se]

b. terceira pessoa do singular (masculino): ['eli] —- $\left[\mathrm{e}^{\mathrm{e}}\right]$

c. terceira pessoa do plural (masculino): ['elis]—_ez]

Kato (2000) propõe que os pronomes fortes duplicados recebem Caso default ${ }^{3}$ pelo fato de não checarem Caso, uma proposta que assumo neste trabalho. No espanhol, à semelhança do PB, esses pronomes recebem Caso nominativo default e, no francês e no inglês, recebem Caso dativo e oblíquo, respectivamente. A evidência que dá suporte a essa distinção é encontrada nos contextos em que o pronome é um predicativo (cf. (20)). Nesses casos, "o nominal não checa caso" (Ibid., p. 14), tal como acontece quando está deslocado à esquerda da frase:

(20) a. It is me.

"Sou eu."

b. C'est moi.

"Sou eu."

c. Soy yo.

"Sou eu." 
Ao centrar minha atenção nas construções com duplicação do sujeito em PB, observo um fato importante: apesar de o pronome que duplica o sujeito no PB ser deficiente como o do francês, a adjacência na primeira língua, conforme observado em (21), pode ser rompida entre o pronome fraco e o verbo, ao contrário do que ocorre em francês (cf. (22)):

(21) Você cê intencionalmente/ sempre lê os livros românticos.

(SILVA, 2004, p. 432)

(22) a. *Il probablement va arriver demain.

(CARDINALETTI, 1997, p. 47)

b. *Toi tu intentionnellement/ souvent lis des livres romantiques. ${ }^{4}$

(SILVA, loc. cit.)

Ao estudarem dois dialetos italianos, o trentino e o fiorentino, línguas de sujeito nulo (ex.: Parlo "Falo"), Brandi e Cordin (1989) distinguem os clíticos sujeitos desses dialetos dos clíticos sujeitos no francês, uma língua de sujeito não-nulo (ex.: *(Je) parle "eu falo"). Embora no trentino, no fiorentino e no francês deva haver adjacência entre o clítico sujeito e o verbo, essas línguas diferem no seguinte aspecto: nas duas primeiras, o clítico sujeito, geralmente, está presente, ocupando uma posição de núcleo $\left(\mathrm{X}^{0}\right)$ e sendo seguido pelo verbo, ao passo que na última ele ocorre em construções com duplicação do sujeito. Por exemplo, quantificadores indefinidos como Personne "ninguém" e Tout "tudo" (cf. (23)) não podem ser duplicados por um clítico sujeito em francês ${ }^{5}$ (cf. AMBAR; POLLOCK, 2002); no trentino e no fiorentino, o clítico sujeito deve manter co-referência com o quantificador à sua esquerda (cf. (24)) (os clíticos encontram-se em negrito):

(23) a. *Personne, il n'a rien dit.

"Ninguém, ele disse nada."

b. *Tout, il est arrivé à la nuit.

"Tudo, ele aconteceu de noite."

(24) a. Nessuno gl'ha detto nulla. (fiorentino)

a'. Nisun l'ha dit niente. (trentino)

"Ninguém ele disse nada." 


\section{b. Tutto gl'è sucesso di notte. (fiorentino) \\ b'. Tut l'è capita de not. (trentino) \\ "Tudo ele aconteceu de noite."}

Portanto, se o clítico sujeito em francês não tem as mesmas propriedades dos clíticos sujeitos do trentino e do fiorentino, resta como alternativa considerálo um pronome fraco (XP) que se encontra na posição-A Spec, AgrSP (cf. ALEXIADOU; ANAGNOSTOPOULOU, 1998 e COSTA; GALVES, 2002). O preenchimento dessa posição faz-se necessário em virtude de o traço-D de Agr ser forte, o que implica dizer que a checagem desse traço faz-se por move do XP, conforme defendem Alexiadou e Anagnostopoulou (op. cit.).

Segundo Cardinaletti (1997), a adjacência requerida entre o pronome deficiente e o verbo no francês não implica dizer que esse pronome seja um clítico como sugerido por Brandi e Cordin (1989), mas tem a ver com o movimento longo do verbo: já que o verbo se move até AgrS, ter-se-á como conseqüência a adjacência entre ele e o pronome deficiente que ocupa o Spec de AgrSP. No PB, ao contrário, a adjacência entre o pronome que duplica o sujeito e o verbo pode ser bloqueada conforme atesta (21), o que vem corroborar a análise de Costa e Galves (op. cit.) de que o movimento do verbo é curto nessa língua.

Assumindo com De Cat (2003) que o DP sujeito em construções com deslocamento à esquerda no francês é um tópico que deve ser identificado por uma categoria dentro do comentário: "[t]he LDed element expresses the topic of the sentence [...]"'6 (Ibid., p. 4), é plausível defender que duplicação do sujeito no francês implica duplicação de um tópico marcado, estando o DP sujeito e o pronome resumptivo ocupando posições sintáticas distintas obrigatoriamente. Essa autora observa que tanto em frases em que o genitivo está topicalizado, sendo retomado por uma categoria interna ao comentário (cf. (25)), quanto nos contextos com duplicação do sujeito, como ilustrado em (26), tem-se a mesma situação: o tópico é retomado por uma categoria pronominal, o que caracteriza uma estrutura de tópico marcado, seguindo a análise de Duarte $(1987,2003)$. Evidências para essa análise correspondem não só à possibilidade de XPs rompendo a adjacência entre esses constituintes (cf. (27)), mas também à presença obrigatória de um corte entoacional entre o tópico e o comentário, situação esta que é similar ao que ocorre em inglês (cf. (28)). Não havendo esse corte, a frase é, por conseguinte, agramatical (cf. (29)): 
(25) Claas, , j'ai pris une photo de ses $_{i}$ chaussettes.

"Claas, eu tirei uma foto de suas meias."

(26) Kester ${ }_{i}, i_{i}$ dit qu'il ${ }_{i}$ aime bien les poissons.

"Kester, ele diz que ele gosta muito de peixe."

(DE CAT, op. cit, p. 11)

(27) a. Pierre, sa femme, il sait qu'elle rentrera ce soir.

"Pedro, sua mulher, ele sabe que ela regressará esta noite."

b. Toi intentionnellement/ souvent tu lis des livres romantiques

"Você intencionalmente/ sempre cê lê os livros românticos."

(COSTA; DUARTE; SILVA, 2004, p. 3)

(28) Watch out! That man, he's got a knife.

«Cuidado! Aquele homem, ele tem uma faca.»

(KAYNE, 2001, p. 6; 9)

(29) Pierre *(//) il vient de téléphoner.

"O Pedro ele acabou de telefonar."

(COSTA; DUARTE; SILVA, 2004, p. 3)

Outra evidência que vem favorecer a análise de De Cat (2003) pode ser encontrada na pesquisa desenvolvida por Galves (2001). Segundo essa autora, "[o]s clíticos sujeitos do francês ocupam a posição de sujeito na sintaxe: se eles co-ocorrem com um NP lexical, este funciona como tópico, e NPs não topicalizáveis não podem ocorrer nesse contexto.” (cf. (30)):

(30) a. Jean, il vient d' arriver.

"O João, ele acabou de chegar."

b. *Personne, il vient d'arriver.

"Ninguém, ele acabou de chegar."

(GALVES, 2001, p. 138)

(31) a. *Chaque enfant, il apporte son livre à l'école.

"Cada criança, ela leva seu livro à escola."

b. *Chaque enfant, je l'ai vu à l'école.

"Cada criança, eu a vi na escola."

(COSTA; DUARTE; SILVA, loc. cit.) 
(32)

*Tout homme, il est mortel.

"Todo homem, ele é mortal."

(DE CAT, op. cit., p. 9)

Com base nessas frases, é possível concluir que sujeitos quantificados como Personne "ninguém" (cf. (30b)), Chaque enfant "cada criança" (cf. (31a) e (31b)) e Tout homme "todo homem" (cf. (32)), ao contrário de DPs definidos, por não poderem ocorrer em estruturas de topicalização, não podem ser duplicados.

\subsection{Uma nova proposta para o português brasileiro}

Assumindo com Costa, Duarte e Silva (2004) que, em determinados contextos estruturais com duplicação do sujeito em $\mathrm{PB}$, o pronome fraco é um $\mathrm{X}^{\mathrm{o}}$ que funciona como uma marca de pessoa que se ancora no núcleo $\mathrm{D}$ e cuja lexicalização é pós-sintática, é plausível argumentar que construções com duplicação do sujeito no PB não estão disponíveis apenas para sujeitos com estatuto de tópico, ${ }^{7}$ ao contrário do que ocorre no francês e no inglês, em que pronomes fracos (XPs) mantêm co-referência com um tópico deslocado à esquerda da frase. Nessa acepção, observem-se as evidências que corroboram essa proposta de análise:

a) Possível ausência de um corte entoacional entre o DP sujeito e o pronome fraco não causa agramaticalidade:

(33) a. A Clarinha ela $_{\mathrm{i}}$ cozinha que é uma maravilha.

b. Eu acho que o povo brasileiro ele $_{\mathrm{i}}$ tem uma grave doença.

c. Eu acho que um trabalho sério ele $_{\mathrm{i}}$ teria que começar por aí.

(DUARTE, 2000, p. 28)

b) Presença de XPs rompendo a adjacência entre o DP sujeito e o pronome fraco torna a frase muito ruim ou mesmo agramatical ${ }^{8}$ :

(34) a. *??Você intencionalmente/ sempre cê lê livros românticos.

b. ??Você, sua mulher, cê deve tratar ela bem.

(SILVA, 2004, p. 439) 
c) Possibilidade de duplicação de sujeitos quantificados por quantificadores como "todo(s)" e "cada" não torna a frase agramatical:

(35) a. Toda criança ela aprende rápido a gostar de Coca-Cola.

b. Todo homem ele odeia se sentir fraco.

(BRITTO, 2000, p. 202)

(36) a. Cada menino ele leva um livro para a escola.

b. Todos os meninos eles levam um livro pra escola.

(COSTA; DUARTE; SILVA, 2004, p. 1, 5)

No que concerne à agramaticalidade da frase em (34a), verifico que Spec, TP não é uma posição licenciada nessa língua em virtude de os advérbios intencionalmente e sempre, quando adjungidos a TP, não poderem romper a adjacência entre o sujeito e o pronome resumptivo. Além disso, o requerimento da adjacência entre o DP sujeito (você) e o pronome resumptivo (cê) traz uma conseqüência para a análise aqui empreendida: construções de duplicação como as que são apresentadas em (33), (35) e (36) não correspondem necessariamente a construções de duplicação de um tópico marcado. Nesse sentido, o sujeito e o pronome resumptivo ocupam uma posição-A, ${ }^{9}$ conforme atesta o efeito de ligação-A em (37):

(37) As mulheres elas $_{\mathrm{i} \text {, }}$ usaram todas os brincos umas das outras.

Em seu artigo intitulado Pronouns and their Antecedents, Kayne (2001), ao trabalhar com a ligação que pode ser estabelecida entre um pronome e seu antecedente, propõe uma análise unificada para as estruturas com deslocamento à esquerda do clítico e de construções em que a co-referência entre DPs (relação pronome-antecedente) é atestada. Segundo ele, em ambos os casos, essa co-referência envolve uma relação de movimento (Move). Inicialmente, observem-se a estrutura em (38) com deslocamento à esquerda do clítico no espanhol e a estrutura em (39) do inglês:

(38) Le doy un libro a Juan.

"A ele, eu dou um livro ao João."

(39) John thinks he is smart.

"O João acha que ele é esperto." 
Na estrutura frásica em (38), o autor argumenta que o DP Juan e o clítico le formam um constituinte duplicado e que juntos correspondem a uma única função- $\theta$ : "Clitic doubling involves a clitic pronoun and an associated DP that together correspond to a single theta role"10 (KAYNE, op. cit., p. 2). Para derivar essa estrutura, ele propõe que, inicialmente, o clítico e o DP duplicado estão fundidos (merged) e, depois, separam-se, possibilitando ao clítico ocupar a posição mais à esquerda da frase. Para tanto, é imprescindível a derivação apresentada em (40):

(40) doy un libro [Juan le] $\rightarrow$

[Juan le $]_{\mathrm{i}}$ doy un libro $\mathrm{t}_{\mathrm{i}} \rightarrow$

Juan $_{\mathrm{j}}\left[\mathrm{t}_{\mathrm{j}} \mathrm{le}_{\mathrm{i}}\right.$ doy un libro $\mathrm{t}_{\mathrm{i}} \rightarrow$ merger de a

a Juan ${ }_{j}\left[t_{i}\right.$ le] doy un libro $t_{i} \rightarrow$

$\left[\left[t_{i} \text { le }\right] \text { doy un libro } t_{i}\right]_{k}$ a Juan $t_{j}$

Similarmente ao início da derivação em (40), na derivação da frase em (41), tendo o antecedente e o pronome os mesmos índices referenciais, implica considerar que eles também formam um único constituinte no início da derivação, havendo, posteriormente, o movimento do DP John para a posição- $\theta^{11}$ de sujeito da oração matriz:

(41) thinks [John he] is smart $\rightarrow$

$\mathrm{John}_{\mathrm{i}}$ thinks $\left[\mathrm{t}_{\mathrm{i}}\right.$ he] is smart

Levando em conta que, nas construções com deslocamento à esquerda dos sujeitos em inglês, uma relação de co-referência entre o antecedente e o pronome é estabelecida (cf. (42)), Kayne propõe que o DP sujeito e o pronome que o duplica formam também um único constituinte:

(42) Watch out! That man, he's got a knife.

«Cuidado! Aquele homem, ele tem uma faca.»

(KAYNE, op. cit., p. 6; 9)

Para derivar uma frase como (42), o pronome e o antecedente que o ccomanda formam, inicialmente, o constituinte [That man he]. Através da aplicação de Move, o DP That man ocupa uma posição deslocada à esquerda da frase. 
Visando estabelecer, portanto, uma análise unificada para os contextos estruturais em que se verifica a relação de co-referência num constituinte como [John he], Kayne (2001, p. 4), seguindo Uriagereka (1995, p. 81), assume que John ocupa a posição de Spec e o pronome ocupa o núcleo desse constituinte, levando-o à formulação da condição em (43):

(43) Extraction of a phrase from within a doubling constituent like [John $h e]$ is limited to extraction of the Spec. ${ }^{12}$

Com base na formulação proposta por Kayne, ergue-se uma questão no que respeita às construções com duplicação dos sujeitos em PB que não correspondem a construções com deslocamento à esquerda: como será possível estabelecer a co-referência entre o antecedente e o pronome se não há movimento do Spec de dentro do constituinte, ao contrário do que ocorre nas construções com deslocamento à esquerda no francês e no inglês? Desse questionamento, resulta que a condição em (43) não é de todo satisfatória para dar conta dessas construções, o que me leva a assumir outra proposta de análise. Assim, a partir da discussão da análise desse autor, é plausível defender que o domínio da teoria da ligação, no que diz respeito à co-referência entre o sujeito e o pronome que o duplica, não se aplica no curso da derivação, mas pós-sintaticamente, conforme será discutido mais adiante.

Já que sujeitos pré-verbais no PB estão na posição-A mais alta da frase e certas construções com duplicação deles não correspondem à duplicação de tópicos marcados, qual será então o lugar na estrutura frásica para hospedar o DP sujeito e o pronome que o duplica? Para essa questão, adoto a seguinte hipótese formulada em Costa, Duarte e Silva (2004): devido ao enfraquecimento da morfologia flexional no PB caracterizado pela perda da especificação gramatical de algumas pessoas do discurso no singular e no plural, a gramática dessa língua tem compensado essa perda pela lexicalização dos traços de pessoa no DP sujeito. Vejam-se, portanto, os paradigmas em PB e em PE, respectivamente, em que é possível verificarmos o enfraquecimento da morfologia de pessoa na primeira língua, ${ }^{13}$ ao contrário da segunda, esta com os morfemas especificando cada pessoa no paradigma verbal, exceto a $2^{\mathrm{a}} \mathrm{p} . \mathrm{pl}($ vós $):^{14}$ 
(44)

\section{QUADRO}

Paradigmas flexionais do PB e do PE

\begin{tabular}{c|c}
\hline PB & PE \\
\hline Eu canto & Eu canto \\
\cline { 2 - 2 } Você/ ele(a)/ a gente canta & Tu cantas \\
Nós cantamos & Você/ ele(a)/ a gente canta \\
\hline Vocês/ eles(as) cantam & Nós cantamos \\
\hline
\end{tabular}

Tomando como quadro teórico a Morfologia Distribuída, a análise proposta para as construções com duplicação do sujeito em PB baseia-se no seguinte fato: o núcleo $\mathrm{D}$, por ser a categoria que ancora a referência do DP à sua interpretação, hospeda o traço de pessoa. Em outras palavras, o nó sintático do núcleo $\mathrm{D}$ enviado à componente morfológica da gramática manipula esse traço que, mais tarde, em Spell-Out, unir-se-á ao traço fonológico. Dessa forma, "o pronome fraco será uma lexicalização póssintáctica do valor desse traço, cuja especificação depende da operação sintáctica Agree que se estabeleceu entre D e o seu especificador, merged em Spec, DP." (cf. COSTA; DUARTE; SILVA, 2004, p. 4). Nessa acepção, é imprescindível que se estabeleça uma configuração Spec/Head entre D e seu Spec. Essa estratégia de lexicalizar o traço de pessoa no núcleo $\mathrm{D}$ aponta para uma reestruturação na gramática do PB no domínio interno do DP, uma opção resultante do processo de mudança por que está passando a morfologia flexional dessa gramática. Veja-se, portanto, a seguinte configuração arbórea:

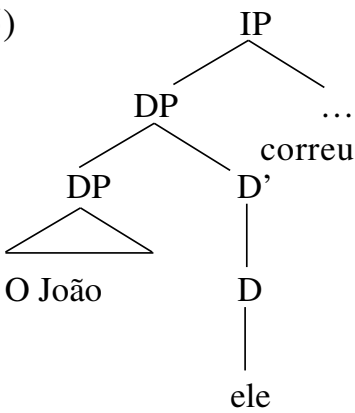


Para a formulação da proposta de análise supracitada, é imprescindível levar em conta a distinção formulada por Embick e Noyer (2001) para dois tipos de morfemas: a) morfema sintático e b) morfema dissociado. O primeiro é predizível a partir do nó sintático, ao passo que o segundo só é inserido póssintaticamente na componente morfológica da gramática. Nesse último caso, a afixação do morfema dissociado se dá independentemente de ter havido movimento sintático.

Uma das evidências para a existência de morfemas dissociados encontra-se numa língua como o sueco. Embick e Noyer (2001, p. 580-581) observam que, nessa língua, ao $\mathrm{N}$ de um DP definido (doravante $\mathrm{D}_{\text {[def] }}$ ) sempre está afixada a marca morfológica de definitude (doravante $\mathrm{DEF}$ ) quando não há outro material dentro do DP ((cf. (46)), ou mesmo quando há outros determinantes definidos visíveis (cf. (47)):

(46) mus-en

casa- DEF

"O rato"

(47) den gamla mus-en

o velho rato-DEF

"O velho rato"

Partindo, portanto, da co-ocorrência de $\mathrm{D}_{\text {[def] }}$ visível com a marca de definitude em N, Embick e Noyer (2001, p. 581) assumem que essa marca corresponde a um morfema dissociado que é inserido pós-sintaticamente. Numa tentativa de explicar a presença obrigatória da marca de definitude em $\mathrm{N}$ no contexto de $\mathrm{D}_{\text {[def] }}$, os autores formulam as seguintes condições com base no que é imposto na PF:

(48) Requirements (imposed at $P F)^{15}$ :

a. The head $\mathrm{N}$ must be marked with definiteness when $\mathrm{D}$ is [def].

b. $D_{\text {[def] }}$ must have a host.

É assumido ainda que, no caso de DPs que não tenham o $\mathrm{D}_{\text {[def] }}$ visível como em (44), ambos os requerimentos são satisfeitos: $N$ carrega a marca de definitude e $\mathrm{D}_{\text {[def] }}$ que sempre é projetado na sintaxe tem o "hospede" $\mathrm{N}$ que a ele se incorpora através de raising de N-para-D. 
Não obstante, para os casos de DPs como em (47), em que o $\mathrm{N}$ não só carrega a marca de definitude -en, mas também possui um determinante definido visível $d$-en, são requeridos na PF processos pós-sintáticos que permitam a atribuição dessa marca nos elementos que a exigem.

Em linhas gerais, Embick e Noyer (2001) argumentam que a atribuição do morfema dissociado [def] a $\mathrm{N}$ pode ser considerada um processo que envolve um certo tipo de concordância entre N e [def]: "[...] Swedish has a requirement to the effect that $\mathrm{N}$ in [def] environments reflects the [def] feature via concord." ${ }^{16}$. Esse processo só se aplica quando necessário em caso de haver motivação dessa atribuição na PF, conforme formulado a seguir:

(49) Assign [def] to the head $\mathrm{N}$ in a DP with the [def] property. ${ }^{17}$

Diante do exposto, é plausível supor que o traço de pessoa ancorado no núcleo $\mathrm{D}$ nas construções de duplicação do sujeito no $\mathrm{PB}$ até aqui analisadas corresponde a um tipo de morfema dissociado. Sendo assim, ele é atribuído na $\mathrm{PF}$ ao nó terminal $\mathrm{D}$, a fim de compensar o enfraquecimento da morfologia flexional a partir da lexicalização do traço morfológico relativo à pessoa. Ademais, conforme já enunciado, a operação Agree é atestada entre D e o seu especificador (ex: (i) O João $\mathrm{ele}_{\mathrm{i}} \ldots$ versus (ii) *O João ${ }_{\mathrm{i}}$ eles $_{\mathrm{i}}$....) à semelhança do que ocorre no sueco entre $\mathrm{N}$ e [def].

Algumas das consequiências teóricas dessa proposta são: a) o pronome fraco em PB, ao contrário do que tem sido assumido, até o momento, não é um XP, mas um $X^{\circ}$ cuja lexicalização do traço de pessoa ocorre póssintaticamente, uma situação não prevista na proposta de classificação dos pronomes por Cardinaletti e Starke (1994) e b) a estrutura com duplicação do sujeito em PB "é mais complexa do que uma estrutura em que um DP simples ocupa a posição Spec, IP, predizendo-se que seja de aquisição tardia, conforme os factos [...]"18 (COSTA; DUARTE; SILVA, 2004, p. 5).

É fato que, embora construções com duplicação do sujeito sejam bastante freqüentes na gramática do falante adulto do PB, há certos DPs indefinidos que resistem a essa duplicação, sobretudo quando se trata de contextos com focalização do sujeito. Vejam-se os contrastes nos pares pergunta-resposta ${ }^{19}$ com DPs definidos e indefinidos com todos os tipos de verbos: 
(50) A: O que é que aconteceu?

B: a. O João (ele) chegou.

b. O João (ele) comeu o bolo.

c. O João (ele) tossiu.

C: a. Algum menino (OK?*ele) chegou.

b. Algum menino (OK?*ele) comeu o bolo.

c. Algum menino (OK?*ele) tossiu.

(51) A: Quem chegou?

B: O João (ele) chegou.

C: Algum menino (?*ele) chegou.

(52) A: Quem comeu o bolo?

B: O João (ele) comeu.

$\mathrm{C}$ : Algum menino (?*ele) comeu.

(53) A: Quem tossiu?

B: O João (ele) tossiu.

C: Algum menino (?*ele) tossiu.

Tendo em vista a impossibilidade de duplicação de DPs indefinidos em virtude de, ao que tudo indica, haver um certo efeito de definitude associado a essa duplicação, proponho que esses DPs estejam ocupando a posição-A mais alta da frase, nomeadamente Spec, AgrSP:20

$$
\left.\left.\left[_{\mathrm{AgrSP}} \mathrm{DP} \mathrm{i}_{\mathrm{i} P} \mathrm{t}_{\mathrm{i}} \mathrm{i}_{\mathrm{T}}, \mathrm{V}_{\mathrm{j}}\left[_{\mathrm{VP}} \mathrm{t}_{\mathrm{i}}\left[\mathrm{V}_{\mathrm{V}}, \mathrm{t}_{\mathrm{j}} \mathrm{DP}\right]\right]\right]\right]\right]
$$

Discorrendo sobre as propriedades das posições-Ae A-barra, Alexiadou e Anagnostopoulou (1988) assumem com May (1985) que as propriedades de escopo de QPs e DPs indefinidos são preservadas quando esses constituintes são movidos para uma posição-A, uma situação que não é verificada no grego. Nessa língua, sujeitos pré-verbais quantificados e indefinidos não possuem escopo ambíguo, ao contrário do que ocorre quando estão em Spec, VP, a única posição-A. Em (55) o DP indefinido Kapios fititis ("algum estudante") tem necessariamente escopo largo sobre o QP kathe arthro ("toda cláusula"), ao passo que, em (56), por estar em sua posição de base, possui escopo largo ou estreito: 
(55) Kapios fititis stihiothetise kathe arthro.

Algum estudante arquivou toda a cláusula

"Algum estudante arquivou toda a cláusula."

(56) stihiothetise kapios fititis kathe arthro.

"Arquivou algum estudante toda a cláusula."

De mais a mais, DPs indefinidos pré-verbais têm, em geral, leitura partitiva no grego, ao passo que, estando em posição pós-verbal, a única leitura disponível é a existencial:

(57) Ena pedhi diavasi to 'Paramithi horis Onoma'.

Uma criança leu o 'Conto de fadas sem um Título'.

"Uma certa criança/ uma das crianças leu 'o Conto de fadas sem um Título."

(58) diavasi ena pedhi to 'Paramithi horis Onoma'.

Leu uma criança o 'Conto de fadas sem um Título'.

"Leu uma criança o 'Conto de fadas sem um Título.'

(ALEXIADOU; ANAGNOSTOPOULOU, 1998, p. 506)

Diferentemente do grego, DPs indefinidos pré-verbais no PB podem ter leitura partitiva ou não, à semelhança do que ocorre no inglês. Seguindo Enç (1991), essa leitura ambígua só pode ser bloqueada se levado em conta o contexto discursivo mais amplo. Na frase em (59), o DP indefinido Algum menino para receber leitura partitiva tem de necessariamente estar incluído num subconjunto de um dado referente já mencionado no domínio do discurso, ao passo que, para possuir leitura [-partitiva], ele deve ter sido mencionado pela primeira vez no discurso, sendo o seu referente novo no sentido absoluto do termo:

(59) Algum aluno entrou na sala durante a reunião. (leitura (+partitiva) ou (-partitiva))

Apesar de DPs sujeitos pré-verbais no PB no domínio intrafrásico estarem ocupando Spec, AgrSP, há evidências empíricas de que, em determinados contextos estruturais, eles podem estar deslocados à esquerda, o que implica considerar que estão num domínio extrafrásico. Um desses contextos que não é produzido pela gramática do PE corresponde às 
construções de tópicos sujeitos analisadas por Galves (1998), em que o argumento que ocupa a posição pré-verbal não corresponde a um sujeito "típico" nos termos de Pontes (1986):

(60) a. O relógio quebrou o ponteiro.

b. O pneu do carro furou.

Nas frases em (60), assumo com Costa e Galves (2002) que os DPs sujeitos pré-verbais ocupam uma posição de adjunção a AgrSP, não havendo pronome resumptivo que os duplique numa posição-A. Segundo esses autores, em virtude da não existência do argumento com função- $\theta$ Agente, Spec, AgrSP não pode ser ocupado. Portanto, uma relação de causa-efeito se instaura: a ausência de um argumento Agente implica ausência de pronome que duplica o sujeito no domínio intrafrásico. Veja-se a impossibilidade de ligação-A (cf. (61)), de um agente implícito como controlador do sujeito das orações finais (cf. (62)) e de advérbios com leitura orientada para o sujeito (cf. (63)):

(61) a. * A revista xerocou suas $_{\mathrm{i}}$ páginas.

b. *O relógio ${ }_{\mathrm{i}}$ quebrou os seus $\mathrm{s}_{\mathrm{i}}$ ponteiros.

(62) a. *O relógio quebrou o ponteiro para atrasar a viagem de meu pai. b. *O pneu do carro furou para aborrecer os passageiros.

(63) a. *O relógio intencionalmente quebrou o ponteiro.

b. *O pneu do carro intencionalmente furou.

Em suma, estando o tópico sujeito numa posição de adjunção a AgrSP e não sendo Spec, AgrSP preenchido por um pronome resumptivo, resta como solução, segundo Costa e Galves (2002), o movimento dos traços-f do verbo de T para AgrS:

$$
\left[_{\mathrm{AgrSP}} \mathrm{DP}_{\mathrm{i}}\left[_{\mathrm{AgrSP}} \operatorname{AgrS}_{\mathrm{i}}\left[_{\mathrm{TP}} \mathrm{V}-\ddot{\mathrm{O}}_{\mathrm{i}}\left[\mathrm{VP}_{\mathrm{VP}} \mathrm{t}_{\mathrm{v}} \text { pro }_{\mathrm{i}}\right]\right]\right]\right]
$$

Ao contrário das construções de tópicos sujeitos, construções de tópicos marcados, conforme analisadas por Duarte (1987) para o PE, são também encontradas no PB. Nesses casos, construções com duplicação do sujeito correspondem a construções com duplicação de tópicos marcados necessariamente (cf. (65b)). Nesse sentido, deve haver um corte entoacional entre o DP deslocado à esquerda e o pronome co-referente nulo ou preenchido 
que ocupa a posição-A Spec, AgrSP. Um fato curioso é que nessas construções o pronome resumptivo é resistente à redução fonológica (cf. (65a)):

(65) a. ?*Você, tenho certeza de que cê vai ganhar o prêmio.

b. Você, tenho certeza de que você vai ganhar o prêmio.

A configuração sintática para uma frase como (65b) terá o DP sujeito, em outras palavras, o tópico marcado, adjungido a AgrSP, estando o pronome resumptivo interno ao domínio frásico:

(66) $\left[_{\mathrm{AgrSP}} \mathrm{DP}_{\mathrm{i}}\left[_{\mathrm{AgrSP}} \operatorname{pro}_{\mathrm{i} /} \mathrm{ele}_{\mathrm{i}}\left[_{\mathrm{TP}} \mathrm{t}_{\mathrm{i}}\left[_{\mathrm{T}}, \mathrm{V}_{\mathrm{j}}\left[_{\mathrm{VP}} \mathrm{t}_{\mathrm{i}}\left[\mathrm{V}_{\mathrm{V}}, \mathrm{t}_{\mathrm{j}} \mathrm{DP}\right]\right]\right]\right]\right]\right]$

Portanto, diante do exposto, é plausível depreender os seguintes fatos no PB:

1) Duas situações podem ser observadas em estruturas com duplicação do sujeito: a) o sujeito e o pronome resumptivo ocupam a mesma posição-A, sendo este uma lexicalização pós-sintática do traço de pessoa no núcleo D e b) o sujeito e o pronome resumptivo ocupam posições sintáticas distintas, assemelhando-se às estruturas com duplicação de sujeitos préverbais no francês e no inglês, em que tópicos marcados são retomados por um pronome co-referente no domínio intrafrásico;

2) DPs indefinidos são resistentes a estruturas de duplicação, sobretudo, em contextos com focalização do sujeito, o que implica argumentar a favor da análise de eles ocuparem uma posição-A;

3) DPs pré-verbais em construções de tópicos sujeitos, seguindo a terminologia de Galves (1998), sempre estão adjungidos a AgrSP.

\section{CONCLUSÃO}

A partir de contra-evidências às análises que defendem que todos os sujeitos pré-verbais estão deslocados à esquerda no $\mathrm{PB}$ nas construções com duplicação dos sujeitos, foi possível defender a idéia de que, em virtude do enfraquecimento da morfologia de flexão verbal nessa língua, o pronome resumptivo, em contextos estruturais específicos, é um $\mathrm{X}^{\mathbf{0}}$ com propriedades de pronome fraco que marca no núcleo $\mathrm{D}$ o traço de pessoa cuja lexicalização se dá pós-sintaticamente. Tal análise sugere, portanto, que a duplicação do 
sujeito em PB não corresponde necessariamente à estratégia de topicalização, tem propriedade distinta das construções com deslocamento à esquerda no francês e no inglês e não deriva do Parâmetro do Sujeito Nulo, em específico, da perda do Princípio Evite Pronome.

\section{NOTAS}

${ }^{1}$ Vale ressaltar a observação feita por um dos pareceristas deste artigo no que se refere às construções de duplicação do sujeito em PB. Segundo ele, tais construções diferem, em efeito pragmático, das construções de "ordem direta" sem duplicação do sujeito. No entanto, tendo em vista essa questão ultrapassar o âmbito deste trabalho, uma vez que se enquadra no âmbito da interface sintaxepragmática, abordá-la-ei em trabalhos futuros.

${ }^{2}$ Costa e Galves (2002, p. 119) observam que o sujeito deslocado na resposta em (6b) tem um comportamento similar ao objeto deslocado na resposta em (i) no sentido de que, sendo um tópico marcado na resposta, ele recebe leitura contrastiva:

(i) A: O que é que o Pedro comeu?

B: A sopa... ele comeu-a, o resto... não sei.

${ }^{3}$ Para a proposta do Caso default, conferir Schütze (2001).

${ }^{4}$ Agradeço a Jair Farias por fornecer-me essa frase do francês.

${ }^{5}$ Agradeço a Jair Farias por fornecer-me as frases do francês em (23).

${ }^{6} \mathrm{O}$ elemento deslocado expressa o tópico da sentença. (Tradução minha.)

${ }^{7}$ Gonçalves (2004) apud Costa, Duarte e Silva (2004) verifica que construções com deslocamento à esquerda no francês só são possíveis com tópicos e estatisticamente relevantes nos dados da aquisição, ao passo que em PB a aquisição dessas construções se dá tardiamente.

${ }^{8}$ Agradeço aos falantes do dialeto maceioense por fornecerem seus julgamentos de gramaticalidade dessas frases.

${ }^{9}$ Para argumentos adicionais de que sujeitos pré-verbais em PB ocupam uma posição-A, conferir Brito (2001) e Silva (2004).

${ }^{10}$ Duplicação do clítico envolve um pronome clítico e um DP associado que juntos correspondem a uma única função- $\theta$. (Tradução minha.) 
${ }^{11}$ Kayne (2001) assume, ao longo de seu artigo, que a posição pré-verbal do

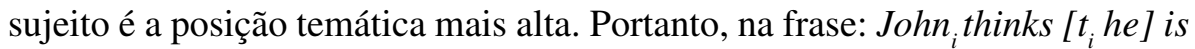
smart, o autor defende que o DP John move-se para a posição temática mais alta da frase que corresponde nessa estrutura à posição pré-verbal de sujeito da frase matriz.

${ }^{12}$ A extração de um sintagma de dentro de um constituinte duplicado como [John he] está limitada à extração do Spec. (Tradução minha.)

${ }^{13}$ Galves (2001, p. 124) verifica que alguns dialetos do PB mostram contraste entre a primeira pessoa do singular e todas as outras: eu canto/você, nós, eles canta. ${ }^{14}$ Os paradigmas de flexão verbal foram elaborados partindo de duas realizações dialetais: a) o dialeto falado na cidade de Maceió (PB) e b) o dialeto falado na cidade de Lisboa (PE).

${ }^{15}$ Requerimentos (impostos na PF):

a. O núcleo $\mathrm{N}$ deve ser marcado com definitude quando $\mathrm{D}$ é [def].

b. $\mathrm{D}_{\text {[def }}$ ] deve ter um hospedeiro. (Tradução minha.)

${ }^{16}$ [...] o sueco tem um requerimento para o efeito que $\mathrm{N}$ em ambientes [def] reflete o traço [def] via concordância. (Tradução minha.)

${ }^{17}$ Atribui-se [def] ao núcleo N num DP com propriedade [def]. (Tradução minha.)

${ }^{18}$ Atualmente, estando desenvolvendo uma pesquisa na área de aquisição da linguagem de orientação ckomskyana, tenho observado, a partir de alguns dados de produção de crianças maceioenses na faixa etária de 2;9 a 3;5 que a predição de as construções com duplicação do sujeito serem adquiridas tardiamente no PB tende a se corroborar.

${ }^{19}$ Agradeço aos falantes do PB por fornecerem seus julgamentos de gramaticalidade das frases. Vale dizer que apenas alguns falantes consultados consideram as frases em (50C) gramaticais quando o indefinido é duplicado por um pronome nos contextos de focalização de toda a frase. Para os demais falantes, essas frases ou são marginais ou agramaticais.

${ }^{20}$ Por questões de espaço, sugiro ao leitor consultar os argumentos apresentados em Silva (2004), que defende a idéia de os sujeitos pré-verbais estarem ocupando uma posição-A no $\mathrm{PB}$, exceto os casos de deslocamento à esquerda e de tópicos sujeitos. 


\section{REFERÊNCIAS}

ALEXIADOU, A.; ANAGNOSTOPOULOU, E. Parametrizing AGR: word order, V-movement and EPP-checking. Natural Language and Linguistic Theory, n. 16, p. 491-539, 1998.

AMBAR, M. M.; POLLOCK, J. Topic vs. comment in some subject inversion sentences in French and Portuguese. Journal of Portuguese Linguistics, v. 1, n. $1,2002$.

BARBOSA, P.; DUARTE, E. L.; KATO, M. A. A distribuição do sujeito nulo no português europeu e no português brasileiro. In: CORREIA, C. N.; GONÇALVES, A. Actas do XVI Encontro Nacional da Associação Portuguesa de Lingüística. Lisboa: Colibri Artes Gráficas, 2001. p. 539-550.

BRANDI, L.; CORDIN, P. Two Italian dialects and the null subject parameter. In: JAEGGLI, O; SAFIR, K. J. The null subject parameter. Dordrecht, London: Kluwer Academic Publishers. 1989. p. 111-142.

BRITO, A. M. Clause structure, subject position and verb movement about the positions of sempre in European Portuguese and Brazilian Portuguese. In: D’ULST, Y. et al. (Ed.). Current Issues in Linguistic Theory. Amsterdam; Philadelphia: John Benjamins Publishing Company, 2001. p. 63-85.

BRITTO, H. Syntactic codification of categorical and thetic juggments in Brazilian Portuguese. In: KATO, M. A.; NEGRÃO, E. V. (Ed.). Brazilian Portuguese and the null subject parameter. Madrid: Iberoamericana, 2000. p. 195-222.

CARDINALETTI, A. Subjects and clause structure. In: HAEGMAN, L. (Ed.). The new comparative syntax. New York: Longman, 1997. p. 33-63.

CARDINALETTI, A.; STARKE, M. The typology of structural deficiency. On the Three Grammatical Classes. January, 1993, May 1994. p. 1-52.

COSTA, J. Null vs overt Spec, TP in European Portuguese. In: QUER, J. et al. (Ed.). Romance Languages and Linguistic Theory 2001: Selected papers from 'Going Romance'. Amsterdam: John Benjamins, 2003. p. 33-49.

COSTA, J.; DUARTE, I; SILVA, C. Construções de redobro em PB: sujeitos tópicos vs. soletração do traço de pessoa. In: I COLÓQUIO INTERNACIONAL DE LÍNGUA PORTUGUESA (CILP), Florianópolis, nov. 2004. p. 1-7. 
COSTA, J.; FIGUEIREDO SILVA, M. C. Nominal and verbal agreement in Portuguese: an argument for Distributed Morphology. Lisboa, 2003. p. 1-35.

COSTA, J.; GALVES, C. External subjects in two varieties of portuguese evidence for a non-unified analysis. In: BEYSSADE, C. et al. Romance languages and linguistic theory 2000, Utrecht, 30 November-2 December. v. 232. Amsterdam; Philadelphia: John Benjamins Publishing Company, 2002. p. 109-125.

DE CAT, C. French dislocation without movement. A minimalist account. Ms., 2003.

DUARTE, I. A construção de topicalização na gramática do português: regência e ligação e condições sobre movimento. 1987. Dissertação (Doutoramento em Lingüística) - Universidade de Lisboa, Lisboa.

DUARTE, M. E. L. The loss of the 'avoid pronoun' principle in Brazilian Portuguese. In: KATO, M. A.; NEGRÃO, E. V. (Eds.). Brazilian Portuguese and the null subject parameter. Madrid: Iberoamericana, 2000. p. 17-36.

DUARTE, I. Relações gramaticais, esquemas relacionais e ordem de palavras. In: MATEUS, M. H. M. et al. Gramática da Língua Portuguesa. 5. ed. rev. aum. Lisboa: Caminho, 2003. p. 275-321.

EMBICK, D.; NOYER, R. Movement operations after syntax. Linguistic Inquiry, v. 32, n. 4, p. 555-595, 2001.

ENÇ, M. The semantics of specificity. Linguistic Inquiry, v. 22, n. 1, p. 1-25, 1991

FIGUEIREDO SILVA, M. C. A posição sujeito no português brasileiro: frases finitas e infinitivas. Campinas: Ed. da UNICAMP, 1996.

GALVES, C. C. Tópicos, sujeitos, pronomes e concordância no português brasileiro. Cadernos de Estudos Lingüísticos, n. 47, p. 19-31, jan./jun. 1998.

GALVES, C. C. Ensaios sobre as gramáticas do português. Campinas, SP: Editora da UNICAMP, 2001.

GONÇALVES, F. Riqueza morfológica e aquisição da sintaxe em português europeu e brasileiro. 2004. Tese (Doutoramento) - Universidade de Évora.

HALLE, M.; MARANTZ, A. Distributed morphology and the pieces of inflection. In: HALE, K.; KEYSER, S. J. (Ed.). The view from building 20: essays in linguistics in honor of Sylvain Bromberger. Current Studies in Linguistics, 24, Cambridge, Massachusetts: The MIT Press, 1993. p. 111-176. 
KATO, M. A. A restrição de monoargumentalidade da ordem VS no português do Brasil. Fórum Lingüístico. Florianópolis, Pós-Graduação em Linguiística, UFSC, 1999, p. 1-21. (no prelo).

KATO, M. A. The partial pro-drop nature and the restricted VS order in Brazilian Portuguese. In: KATO, M. A.; NEGRÃO, E. V. (Ed.). Brazilian Portuguese and the null subject parameter. Madrid: Vervuert, Iberoamericana, 2000. p. 223-258. KAYNE, R. K. Pronouns and antecedents. New York University, Jun. 2001. MAY, R. Logical form. Cambridge, Massachesetts: MIT Press. 1985.

PONTES, E. Sujeito: da sintaxe ao discurso. São Paulo: Ática; Brasília, INL, 1986.

SCHÜTZE, C. T. On the nature of default Case. Syntax, v. 4, n. 3, p. 205-238, dez. 2001.

SILVA, C.R.T. A natureza de AGR e suas implicações na ordem VS: um estudo comparativo entre o português brasileiro e o português europeu. 2004. Tese (Doutorado em Lingüística) - Universidade Federal de Alagoas, Maceió.

URIAGEREKA, J. Aspects of the syntax of clitic placement in Western Romance. Linguistic Inquiry, n. 26, p. 79-123, 1995.

VANCE, B. S. Null subjects and syntactic change in Medieval French. 1989. Tese (Doutorado) - University of Cornell. 